6. Hazardous Products Act, R.S.C. 1985, c. H-3.

7. Tong S, von Schirnding YE, Prapamontol T. Environmental lead exposure: a public health problem of global dimensions. Bull World Health Organ 2000;78(9):1068-77.

DOI:10.1503/cmaj.1040533

\section{[One of the authors responds:]}

T ead exposure in children is equivaUlent to alcohol exposure during pregnancy: there is no safe dose. No threshold value (below which lead has no apparent effect) has been identified. ${ }^{1}$ Warren Bell and Kelly O'Grady are certainly right in saying that we have no recent data on lead levels in Canadian children. When we mentioned in our article that lead poisoning was rare in Canada, ${ }^{2}$ we should have specified that this statement refers to cases requiring chelation therapy. Through discussions with medical toxicology colleagues working in Toronto and Montréal, I was able to identify only 7 cases in the past 10 years in which children required chelation for lead poisoning in those 2 cities: 3 children who were poisoned by unknown sources, ${ }^{3} 2$ children who had recently immigrated to Canada and were most likely poisoned in their countries of origin, 1 autistic child with pica and the case presented recently in CMA7. ${ }^{2}$ Others may have existed but not come to the attention of medical toxicologists, but in those cases the levels were probably above the intervention level of $0.48 \mathrm{mmol} / \mathrm{L}$ but below the recognized chelation threshold of $2.17 \mathrm{mmol} / \mathrm{L}^{4}{ }^{4}$

We chose to present the case of the 4-year-old boy in CMA7 to illustrate that lead poisoning can occur if a child with pica eats paint with lead levels below those set by Canadian law. Many physicians think that such paint is lead free, but, as Kathleen Cooper points out, this is not the case. Blood lead level should be determined for any child with pica, regardless of the age of the child's home, because eating a large quantity of chips of so-called "lead-free" paint can result in lead levels that require intervention with or without chelation.

\section{Benoit Bailey}

Department of Pediatrics

Hôpital Sainte-Justine

Montréal, Que.

\section{References}

1. Bellinger DC. Lead. Pediatrics 2004;113:1016-22.

2. Lavoie PM, Bailey B. Lead poisoning from "lead-free" paint. CMA7 2004;170(6):956.

3. Bailey B, Theis JGW, Joshi P. Lead poisoning: three moderate to severe cases in school-aged children without an apparent source [abstract]. Clin Invest Med 1996;19(Suppl 3):S36.

4. Managing elevated blood lead levels among young children: recommendations from the advisory committee on childhood lead poisoning prevention. Atlanta: Centers for Disease Control and Prevention; 2002 Mar. Available: www.cdc.gov/nceh/lead /CaseManagement/caseManage_main.htm (accessed 2004 July 30).

DOI:10.1503/cmaj.1040745

\section{Possible causes of cognitive decline}

Two things came to mind from 1 reading the report by Jessica Simon and associates, ${ }^{1}$ which thoroughly documents the cause of cognitive decline, seizure and stroke in a 52-year-old man as a rare genetic variation. My questions are inspired in part by the negative family history and the necessary supposition of de novo mutation. Was the patient tested for elevation of homocysteine? This marker is associated with geneti- 